\title{
STUDI IDENTIFIKASI DAN PENANGGULANGAN GENANGAN BANJIR DI JALAN CAK DOKO KELURAHAN OETETE - KOTA KUPANG
}

\author{
Priska Gardeni Nahak ${ }^{1}$, Melchior Bria ${ }^{2}$, Oktaviani Nenabu ${ }^{3}$
}

\begin{abstract}
Abstrak :
Genangan air di Jalan Cak Doko khususnya di depan SMA Negeri 1 Kupang, sudah sangat memprihatinkan, karena genangan yang terjadi bisa mencapai ketinggian hingga $0.75 \mathrm{~m}$, sehingga sangat mengganggu aktivitas lalulintas di lokasi tersebut. Genangan air di ruas jalan ini sering menyebabkan kemacetan karena, kendaraan yang melewatinya harus mengurangi kecepatan untuk menghindari cipratan air dan kemungkinan adanya lubang pada jalan, bahkan tak jarang ada kendaraan yang mogok karena mesin kendaraan tiba-tiba mati. Selain itu, genangan air tersebut juga dapat menyebabkan kerusakan jalan yang berpotensi membentuk lubang atau cekungan yang membuat jalan tidak rata sehingga rawan kecelakaan. Dengan kondisi tersebut, maka diperlukan suatu studi untuk mengevaluasi dan menentukan upaya penanganan terhadap permasalahan genangan air/banjir yang ada di Kota Kupang, khususnya di Jalan Cak Doko Kelurahan Oetete. Berdasarkan hasil identifikasi di lapangan terhadap jaringan drainase yang ada di lokasi studi, terlihat bahwa saluran drainase secara umum sudah tidak berfungsi dengan baik, karena di dalam saluran terdapat banyak sekali sedimen dan sampah-sampah, baik itu sampah organik maupun sampah non organik sehingga menyebabkan penyempitan saluran. Genangan banjir di jalan Cak Doko (depan SMAN I) terjadi karena beberapa hal, antara lain adanya perubahan penggunaan lahan, di mana banyak daerah resapan yang kini telah beralih fungsi menjadi kawasan perumahan, sekolah, dan gedung lainnya, selain itu lahan-lahan kosong di sekitar gedung dan permukiman, banyak yang sudah dibeton, atau dipaving, sehingga mengurangi lahan untuk peresapan, serta adanya penyempitan saluran akibat sedimen dan sampah, sehingga saluran drainase tidak lagi mampu menampung air hujan, yang akhirnya menyebabkan luapan yang menggenangi daerah-daerah cekungan, terutama di sekitar jalan Cak Doko. Berdasarkan hasil evaluasi debit banjir rencana periode kala ulang 5 tahun terhadap kapasitas saluran eksisting diperoleh kapasitas saluran (Qs) lebih kecil dari debit banjir rencana (Qr) sehingga kapasitas saluran eksisting tidak dapat menampung debit banjir yang terjadi. Saluran drainase eksisting juga tidak berfungsi dengan baik yang disebabkan terdapat banyak sekali sedimen dan sampah baik itu sampah organik maupun sampah non organik yang masuk ke dalam saluran sehingga menyebabkan penyempitan saluran. Dari hasil evaluasi kondisi debit banjir rencana terhadap kapasitas saluran eksisting, maka diperoleh pada ruas 1 sampai ruas 6 kapasitas saluran (Qs) lebih kecil dari debit banjir rencana (Qr), sehingga saluran drainase pada ruas 1 sampai ruas 6 tersebut tidak dapat menampung debit banjir rencana. Oleh kerena itu, perlu direkomendasikan untuk merencanakan dimensi saluran berdasarkan hasil perhitungan debit banjir rencana (Qr) kala ulang 5 tahun agar dapat menampung dan mengalirkan debit air hujan dan debit air kotor yang terjadi.
\end{abstract}

Kata Kunci: Genangan Banjir, Saluran Drainase \& Sumur Resapan.

Nahak ${ }^{1}$, Bria $^{2}$, Adalah Dosen Jurusan Teknik Sipil Politeknik Negeri Kupang 


\section{PENDAHULUAN}

Kota Kupang sebagai Ibu Kota Provinsi menjadi pusat segala kegiatan pemerintahan, perekonomian dan kebudayaan. Sebagai ibu kota Propinsi, Kota Kupang juga menjadi salah satu tujuan urbanisasi, akibatnya terjadi peningkatan jumlah penduduk yang semakin pesat dari tahun ketahun. Dengan meningkatnya jumlah penduduk, kebutuhan akan tempat tinggalpun semakin meningkat. Hal ini bisa terlihat dari banyaknya kawasan hutan, pertanian, dan daerah terbuka hijau lainnya, kini telah beralih fungsi menjadi kawasan permukiman, perkantoran dan perekonomian.

Kawasan hutan, pertanian dan daerah terbuka hijau lainnya, merupakan daerah resapan air hujan yang baik, dimana air hujan yang turun diserap dan akan disimpan di dalam tanah sebagai air tanah yang sangat berguna untuk memenuhi kebutuhan air bersih bagi masyarakat. Dengan demikian berarti air hujan tidak akan mengalir ke sembarang tempat yang pada akhirnya akan terbuang percuma ke laut.

Dengan beralih fungsinya kawasan hutan, pertanian dan kawasan hijau lainnya menjadi kawasan permukiman, perkantoran ataupun perekonomian, maka daerah resapan air pun akan menjadi berkurang. Hal ini akan menyebabkan air hujan yang turun banyak yang tidak terserap ke dalam tanah, tetapi akan menjadi aliran permukaan (run off) yang akan membanjiri/menggenangi daerah-daerah cekungan, dan daerah yang lebih rendah.

Permasalahan genangan air di Kota Kupang sudah sangat memprihatinkan. Karena pada saat musim hujan, hampir sebagian besar jalan raya di Kota Kupang mengalami genangan air, terutama jalan raya yang terdapat pada daerah-daerah cekungan maupun di tempat lain yang memungkinkan air tidak dapat mengalir. Genangan air di ruas jalan dapat menyebabkan berkurangnya luas jalan yang dapat dilalui kendaraan. Akibatnya kendaraan yang melewati ruas jalan tersebut terpaksa bergantian melewati ruas jalan tersisa yang tidak tergenang, sehingga dapat menimbulkan kemacetan panjang. Namun tak jarang ditemui kendaraan yang nekat melewati genangan air yang pada akhirnya mogok karena mesin kendaraan tiba-tiba mati. Selain itu, genangan air juga dapat menyebabkan kerusakan jalan yang berpotensi membentuk lubang atau cekungan yang membuat jalan tidak rata sehingga rawan kecelakaan.

Permasalahan genangan air di Kota Kupang diperparah dengan kondisi drainase perkotaan yang buruk. Berdasarkan data master plan dari Sub Dinas Cipta Karya banyak saluran drainase di Kota Kupang, yang sudah tidak berfungsi sebagaimana mestinya sehingga sering terjadi luapan air pada musim hujan. Beberapa daerah yang sering terjadi luapan air antara lain: Kelurahan Oepura, Kelurahan Oetete, Kelurahan Oebufu, Kelurahan Oesapa, Kelurahan Nunleu, dll. Dalam penelitian ini yang menjadi daerah tinjauan yaitu di kawasan Kelurahan Oetete khususnya di Jalan Cak Doko (Depan SMA Negeri 1 Kupang).

Genangan air di Jalan Cak Doko khususnya di depan SMA Negeri 1 Kupang, sudah sangat memprihatinkan, karena genangan yang terjadi bisa mencapai ketinggian hingga $0.75 \mathrm{~m}$, sehingga sangat mengganggu aktivitas lalulintas di lokasi tersebut. Genangan air di ruas jalan ini sering menyebabkan kemacetan karena, kendaraan yang melewatinya harus mengurangi kecepatan untuk menghindari cipratan air dan kemungkinan adanya lubang pada jalan, bahkan tak jarang ada kendaraan yang mogok karena mesin kendaraan tiba-tiba mati. Selain itu, genangan air tersebut juga dapat menyebabkan kerusakan jalan yang berpotensi membentuk lubang atau cekungan yang membuat jalan tidak rata sehingga rawan kecelakaan.

Dengan kondisi tersebut, maka diperlukan suatu studi untuk mengevaluasi dan menentukan upaya penanganan terhadap permasalahan genangan air/banjir yang ada di Kota Kupang, khususnya di Jalan Cak Doko Kelurahan Oetete.

\section{TINJAUAN PUSTAKA Pengertian Drainase}

Adapun beberapa pengertian drainase dari beberapa pendapat antara lain: 
1.Drainase adalah bangunan air yang ditujukan untuk mengendalikan kelebihan air, baik yang berasal dari air hujan, rembesan, aliran air dari hulu dan hilir, pada suatu kawasan seperti: kawasan pemukiman, perdagangan, perindustrian, perkantoran, bandara, lapangan olahraga, dan kawasan pertanian, (Kamiana, 2011:2).

2.Drainase berasal dari bahasa Inggris 'drainage' mempunyai arti mengalirkan, menguras, membuang, atau mengalirkan air. Dalam bidang teknik sipil, drainase secara umum dapat didefenisikan sebagai suatu tindakan teknis untuk mengurangi kelebihan air, baik yang berasal dari air hujan, rembesan, maupun kelebihan air irigasi dari suatu kawasan atau lahan, sehingga fungsi kawasan atau lahan tidak terganggu. Secara umum drainase dapat didefenisikan sebagai serangkaian bangunan air yang berfungsi untuk mengurangi dan atau membuang kelebihan air dari suatu kawasan/ lahan, sehingga lahan dapat difungsikan secara optimal, (Suripin, 2004:7).

\section{Perencanaan Hidrolis Saluran Drainase}

Perhitungan penampang basah didasarkan pada debit banjir (Q) dan kecepatan (V) menggunakan rumus sebagai berikut :

$$
\begin{aligned}
& \mathrm{Q}=\mathrm{A} \cdot \mathrm{V} . \\
& \mathrm{A}=\mathrm{Q} / \mathrm{V}
\end{aligned}
$$

Keterangan :

$\mathrm{A}=$ luas penampang basah saluran $\left(\mathrm{m}^{2}\right)$

$\mathrm{Q}=$ debit banjir rencana $\left(\mathrm{m}^{3} / \mathrm{dtk}\right)$

$\mathrm{V}=$ kecepatan aliran $(\mathrm{m} / \mathrm{dtk})$

Dalam Perencanaan desain kecepatan saluran dapat dihitung dengan menggunakan rumus yang dikemukakan oleh Manning dan Strickler:

Rumus Manning :

$$
\mathrm{V}=\frac{1}{\mathrm{n}} \cdot \mathrm{R}^{2 / 3} \cdot \mathrm{I}^{1 / 2}
$$

Rumus Strickler :

$\mathrm{V}=\mathrm{K} \mathrm{R}^{2 / 3} \mathrm{I}^{1 / 2}$

$\mathrm{I}=\mathrm{V}^{2} /\left(\mathrm{K}^{2} \mathrm{R}^{4 / 3}\right)$
Keterangan :

$\mathrm{Q}=$ debit saluran $\left(\mathrm{m}^{3} / \mathrm{dtk}\right)$

$\mathrm{V}=$ kecepatan aliran $(\mathrm{m} / \mathrm{dtk})$

$\mathrm{n} \quad=$ koefisien kekasaran manning (Tabel 2.1)

$\mathrm{K}=$ koefisien kekasaran strickler (Tabel 2.2)

$\mathrm{A}=$ luas penampang basah saluran $\left(\mathrm{m}^{2}\right)$

$\mathrm{R}=$ jari-jari hidrolik $(\mathrm{m})$

$\mathrm{I}=$ kemiringan dasar saluran

Tabel 2.1. Tipikal Harga Koefisien Kekesaran Manning $n$

\begin{tabular}{|l|l|}
\hline \multicolumn{1}{|c|}{ Bahan Dinding Saluran } & \multicolumn{1}{c|}{$\mathbf{n}$} \\
\hline Besi tuang dilapis & 0,014 \\
\hline Kaca & 0,010 \\
\hline Saluran beton & 0,013 \\
\hline Bata dilapis mortar & 0,015 \\
\hline Pasangan batu disemen & 0,025 \\
\hline Saluran tanah bersih & 0,022 \\
\hline Saluran tanah & 0,030 \\
\hline $\begin{array}{l}\text { Saluran dengan dasar batu dan } \\
\text { tebing rumput }\end{array}$ & 0,040 \\
\hline Saluran pada galian batu padas & 0,040 \\
\hline
\end{tabular}

Sumber: Triadmodjo, (2003:113)

Tabel 2.2. Harga Koefisien Kekesaran Stricklerk

\begin{tabular}{|c|l|l|}
\hline No & \multicolumn{1}{|c|}{ Jenis Saluran } & k \\
\hline 1 & Saluran tanah: & \\
\hline & $\mathrm{Q}<1$ dan saluran tersier & 35 \\
\hline & $1<\mathrm{Q}<5$ & 40 \\
\hline & $5<\mathrm{Q}<10$ & 42,5 \\
\hline & $\mathrm{Q}>10$ & 45 \\
\hline 2 & Satu sisi talud pasangan & 42 \\
\hline 3 & $\begin{array}{l}\text { Kedua talud saluran pasangan, } \\
\text { dasar tanah }\end{array}$ & 45 \\
\hline 4 & $\begin{array}{l}\text { Kedua talud dan dasar saluran } \\
\text { pasangan }\end{array}$ & 50 \\
\hline 5 & Satu sisi talud dari beton & 45 \\
\hline 6 & $\begin{array}{l}\text { Kedua talud saluran dari beton, } \\
\text { dasar tanah }\end{array}$ & 50 \\
\hline 7 & $\begin{array}{l}\text { Kedua talud dan dasar saluran dari } \\
\text { beton }\end{array}$ & 70 \\
\hline 8 & $\begin{array}{l}\text { Saluran dari pasangan tegak dan } \\
\text { diplester }\end{array}$ & 75 \\
\hline
\end{tabular}

Sumber: Kriteria Perencanaan-03,(1986) 


\section{Sistem Drainase Permukaan Jalan}

Sistem drainase permukaan jalan terdiri dari: kemiringan melintang perkerasan dan bahu jalan, selokan atau saluran samping, goronggorong dan saluran penangkap (Gambar 2.1).

Tabel 2.3. Kemiringan Melintang Perkerasan dan Bahu Jalan

\begin{tabular}{|l|l|l|}
\hline No & $\begin{array}{c}\text { Jenis lapisan } \\
\text { perkerasan jalan }\end{array}$ & $\begin{array}{c}\text { Kemiringan } \\
\text { melintang normal } \\
\mathbf{i}(\%)\end{array}$ \\
\hline 1 & Beraspal, beton & $2 \%-3 \%$ \\
\hline 2 & $\begin{array}{l}\text { Japat (jalan yang } \\
\text { padat) }\end{array}$ & $2 \%-4 \%$ \\
\hline 3 & Krikil & $3 \%-6 \%$ \\
\hline 4 & Tanah & $4 \%-6 \%$ \\
\hline
\end{tabular}

Sumber: SNI 03-3424, (1994:5)

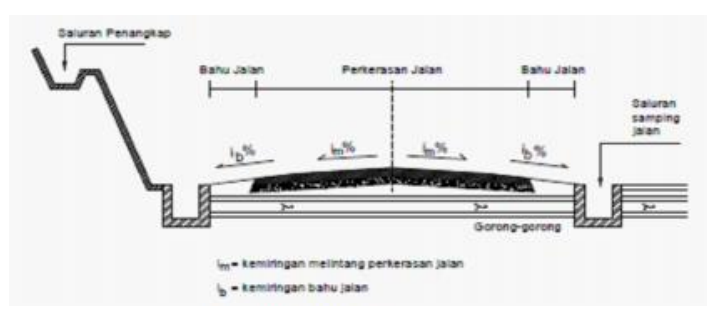

Gambar 2.1. Sistem Drainase Permukaan Sumber:SNI 03-3424, (1994:4)

Tabel 2.4. Kecepatan Aliran Air yang Diizinkan Berdasarkan Jenis Material

\begin{tabular}{|l|c|}
\hline \multicolumn{1}{|c|}{ Jenis Bahan } & $\begin{array}{c}\text { Kecepatan Aliran } \\
\text { Air Yang Diizinkan } \\
\text { (m/detik) }\end{array}$ \\
\hline Pasir halus & 0,45 \\
\hline Lempungkepasiran & 0,50 \\
\hline Lanau aluvial & 0,60 \\
\hline Kerikil halus & 0,75 \\
\hline Lempungkokoh & 0,75 \\
\hline Lempungpadat & 1,10 \\
\hline Kerikil kasar & 1,20 \\
\hline Batu-batubesar & 1,50 \\
\hline Pasangan batu & 1,50 \\
\hline Beton & 1,50 \\
\hline Beton tertulang & 1,50 \\
\hline
\end{tabular}

Sumber: SNI 03-3424, (1994:7)
Tabel 2.5. Kemiringan Saluran versus Kecepatan Rata-Rata Aliran

\begin{tabular}{|c|c|}
\hline $\begin{array}{c}\text { Kemiringan } \\
\text { Saluran I (\%) }\end{array}$ & $\begin{array}{c}\text { Kecepatan Rata-Rata } \\
\text { V (m/dtk) }\end{array}$ \\
\hline$<1$ & 0.40 \\
\hline $1-2$ & 0.60 \\
\hline $2-4$ & 0.90 \\
\hline $4-6$ & 1.20 \\
\hline $6-10$ & 1.50 \\
\hline $10-15$ & 2.40 \\
\hline
\end{tabular}

Sumber : Hasmar, (2011:20)

Tabel 2.6. Hubungan Kemiringan Selokan Samping Jalan (i) dan Jenis Meterial

\begin{tabular}{|l|c|}
\hline \multicolumn{1}{|c|}{ Jenis Material } & $\begin{array}{c}\text { Kemiringan Selokan } \\
\text { Samping } \mathrm{i}(\%)\end{array}$ \\
\hline Tanah asli & $0-5$ \\
\hline Kerikil & $5-7,5$ \\
\hline Pasangan & 7,5 \\
\hline
\end{tabular}

Sumber: SNI 03-3424, (1994:7)

Tabel 2.7. Hubungan Kemiringan Selokan Samping Jalan \& Jarak Pematah Arus

\begin{tabular}{|c|c|c|c|c|c|}
\hline $\mathrm{i}(\%)$ & $6 \%$ & $7 \%$ & $8 \%$ & $9 \%$ & $10 \%$ \\
\hline $\mathrm{L}(\mathrm{M})$ & $16 \mathrm{M}$ & $10 \mathrm{M}$ & $8 \mathrm{M}$ & $7 \mathrm{M}$ & $6 \mathrm{M}$ \\
\hline
\end{tabular}

Sumber: SNI 03-3424, (1994:8)

\section{Dimensi Saluran}

Berikut diuraikan beberapa jenis dimensi saluran yaitu, (SNI 03-3424, 1994:20) :

1). Saluran Atau Selokan Bentuk Segi Empat Saluran drainase bentuk segi empat tidak banyak membutuhkan ruang. Saluran ini berfungsi untuk menampung dan menyalurkan debit limpasan yang besar. 


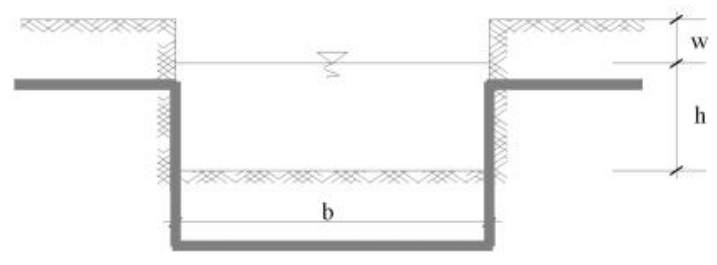

Gambar 2.2. Penampang Bentuk Segi Empat

$$
\text { Sumber : SNI 03-3424, (1994:21) }
$$

Untuk mendimensi saluran persegi dapat digunakan persamaan sebagai berikut (Hasmar, 2011:22) :

a) Luas penampang basah (Fs) : $\mathrm{Fs}=\mathrm{b} . \mathrm{h}$

b) Keliling basah (Ps) :

$$
\mathrm{Ps}=\mathrm{b}+2 . \mathrm{h}
$$

c) Radius Hidrolik (Rs) :

$$
\mathrm{R}=\mathrm{Fs} / \mathrm{Ps}
$$

d) Lebar penampang (b) :

$$
\mathrm{b}=0.75 . \mathrm{h}
$$

Keterangan :

$\mathrm{w}=$ Tinggi jagaan $(\mathrm{m})$

$\mathrm{h}=$ Tinggi penampang basah $(\mathrm{m})$

$\mathrm{b}=$ Lebar dasar saluran $(\mathrm{m})$

2). Saluran Atau Selokan Bentuk Trapesium

Saluran bentuk trapesium merupakan saluran drainase yang berfungsi untuk menampung debit limpasan dalam skala besar. Bentuk saluran ini dapat digunakan pada daerah yang masih tersedia lahan.

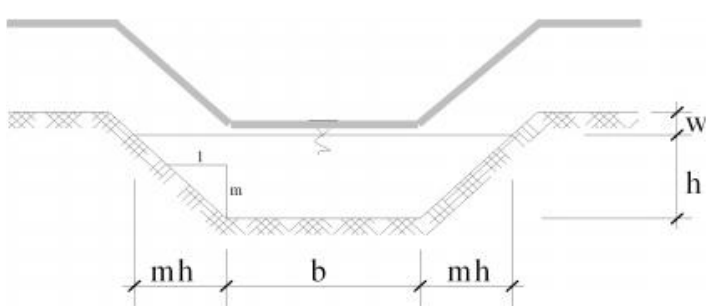

Gambar 2.3. Penampang Bentuk Trapesium Sumber: SNI 03-3424, (1994:20)

Pada penampang melintang saluran trapesium dimensinya dinyatakan sebagai berikut:
$A=(b+m h) . h$

$\mathrm{P}=\mathrm{b}+2\left[\sqrt{\left\{(\mathrm{mh})^{2}+(\mathrm{h})^{2}\right\}}\right]$

$\mathrm{R}=\frac{\mathrm{A}}{\mathrm{P}}$

Keterangan :

$\mathrm{b}=$ lebar dasar saluran $(\mathrm{m})$

$\mathrm{h}=$ tinggi muka air rencana $(\mathrm{m})$

$\mathrm{m}=$ kemiringan talud $=1: \mathrm{m}$

$\mathrm{A}=$ luas penampang basah saluran $\left(\mathrm{m}^{2}\right)$

$\mathrm{P}=$ keliling basah saluran $(\mathrm{m})$

$\mathrm{R}=$ jari-jari hidrolis $(\mathrm{m})$

Tabel 2.8. Kemiringan Talud Berdasarkan Besarnya Debit

\begin{tabular}{|c|c|}
\hline $\begin{array}{c}\text { Debit air } \mathbf{Q} \\
\left(\mathbf{m}^{\mathbf{3}} / \mathbf{d e t i k}\right)\end{array}$ & Kemiringan talud \\
\hline $0,00-0,75$ & $1: 1$ \\
\hline $0,75-15$ & $1: 1,5$ \\
\hline $15-80$ & $1: 2$ \\
\hline
\end{tabular}

Sumber: SNI 03-3424, (1994:21)

\section{3). Saluran Berbentuk Segitiga}

Potongan melintang saluran yang berbentuk segitiga dengan kemiringan sisi terhadap garis vertikal, $\theta$, dan kedalaman air, $\mathrm{h}$ (Gambar 2.13), maka penampang basah (A) dan keliling basah $(\mathrm{P})$ dapat ditulis sebagai berikut :

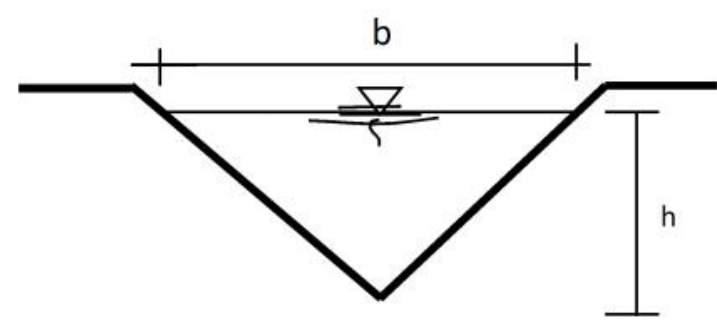

Gambar 2.4. Penampang Berbentuk Segitiga Sumber: SNI 03-3424, (1994:22)

$$
\begin{aligned}
& A=h^{2} \ldots \ldots \\
& P=2 h \quad 2 \\
& R=1 / 4 h " 2 \\
& b=2 h \ldots \ldots .
\end{aligned}
$$




\section{| 113 | JUTEKS Jurnal Teknik Sipil Volume 2 Nomor 2 Oktober 2017}

Keterangan :

$A=$ luas penampang basah saluran $\left(\mathrm{m}^{2}\right)$

$\mathrm{P}=$ keliling basah saluran $(\mathrm{m})$

$\mathrm{R}=$ jari-jari hidrolis $(\mathrm{m})$

$\mathrm{b}=$ lebar dasar saluran $(\mathrm{m})$

$\mathrm{h}=$ tinggi muka air $(\mathrm{m})$

\section{4). Saluran Bentuk Lingkaran/Gorong-}

\section{Gorong :}

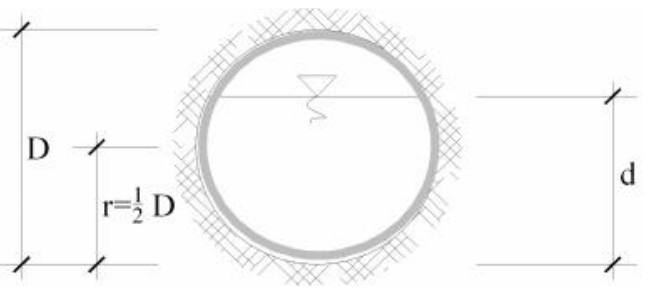

Gambar 2.5. Penampang Berbentuk Lingkaran/Gorong-Gorong

Sumber: SNI 03-342, (1994:23)

Pada penampang melintang, dimensi gorong-gorong dinyatakan sebagai berikut: $\mathrm{d}=0,80 \mathrm{D}$

$\mathrm{A}=\frac{1}{8}(\theta-\sin \theta) \mathrm{D}^{2}$

$\mathrm{P}=2 \mathrm{r}$

$\theta=4,5$ radial

$$
\mathrm{R}=\frac{\mathrm{A}}{\mathrm{P}}
$$

Keterangan :

$\mathrm{d}=$ tinggi selokan yang tergenang air (m)

$\mathrm{D}=$ garis tengah saluran atau selokan bentuk lingkaran $(\mathrm{m})$

A = luas penampang basah $\left(\mathrm{m}^{2}\right)$

$\mathrm{P}=$ keliling basah $(\mathrm{m})$

$\mathrm{r} \quad=$ jari-jari lingkaran $(\mathrm{m})$

$\theta=$ besarnya sudut dalam radial

$\mathrm{R}=$ jari-jari hidrolik

\section{Tinggi Jagaan}

Tinggi jagaan berfungsi untuk :

a). Menaikan muka air di atas muka air maksimum b). Mencegah kerusakan tanggul saluran

Tabel 2.9. Tinggi Jagaan

\begin{tabular}{|c|c|c|c|}
\hline \multirow{2}{*}{$\begin{array}{c}\text { Debit } \\
\text { rencana }\end{array}$} & \multirow{2}{*}{$\begin{array}{c}\text { Saluran } \\
\text { (m/dtk) }\end{array}$} & \multicolumn{2}{|c|}{ Saluran pasangan } \\
\cline { 3 - 4 }$(\mathbf{m})$ & $\begin{array}{c}\text { Tanpa } \\
\text { tanggul }(\mathbf{m})\end{array}$ & $\begin{array}{c}\text { Dengan } \\
\text { tanggul }(\mathbf{m})\end{array}$ \\
\hline$\leq 0,5$ & 0,40 & 0,20 & 0,40 \\
\hline $0,50-1,5$ & 0,50 & 0,20 & 0,50 \\
\hline $1,50-5,0$ & 0,60 & 0,25 & 0,60 \\
\hline $5,0-10,0$ & 0,75 & 0,30 & 0,75 \\
\hline $10,0-15,0$ & 0,85 & 0,40 & 0,85 \\
\hline$>15,0$ & 1,00 & 0,50 & 1,00 \\
\hline
\end{tabular}

Sumber: Kriteria Perencanaan-03, (1986:43)

Tinggi jagaan (W) untuk selokan samping bentuk trapesium dan segi empat ditentukan berdasarkan rumus, (SNI 03-3424, 1994:24) :

$\mathrm{W}=\sqrt{0,5 \mathrm{~h}}$

Keterangan :

$\mathrm{W}=$ tinggi jagaan $(\mathrm{m})$

$\mathrm{h}=$ tinggi muka air $(\mathrm{m})$

Untuk menghitung kemiringan selokan samping dan gorong-gorong pembuang air digunakan rumus :

$\mathrm{V}=1 / \mathrm{n}\left(\mathrm{R}^{2 / 3}\right)(\mathrm{i})^{1 / 2}$

$\mathrm{i}=\left[\frac{V \cdot n}{R}\right]^{2}$

Keterangan :

$\mathrm{V}=$ kecepatan aliran $(\mathrm{m} / \mathrm{dtk})$

$\mathrm{n} \quad=$ koefisien kekesaran manning (Tabel 2.1)

$\mathrm{R}=\mathrm{A} / \mathrm{P}=$ jari-jari hidrolik

A = luas penampang basah $\left(\mathrm{m}^{2}\right)$

$\mathrm{P}=$ keliling basah $(\mathrm{m})$

$\mathrm{i}=$ kemiringan saluran yang diizinkan

\section{Kemiringan Tanah}

Kemiringan tanah di tempat dibuatnya fasilitas selokan gorong-gorong ditentukan dari hasil pengukuran di lapangan dihitung dengan rumus, (SNI 03-3424, 1994:25) :

$i=\frac{t 1-t_{2}}{L} \times 100 \%$ 
Keterangan :

$\mathrm{i} \quad=$ kemiringan lahan eksisting pada lokasi saluran

$\mathrm{t}_{1} \quad$ = tinggi tanah di bagian tertinggi $(\mathrm{m})$

$\mathrm{t}_{2} \quad=$ tinggi tanah di bagian terendah $(\mathrm{m})$

$\mathrm{L} \quad$ = panjang saluran $(\mathrm{m})$

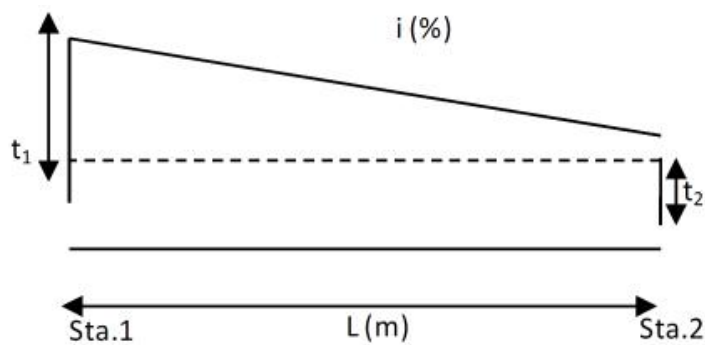

Gambar 2.5. Kemiringan Tanah

Sumber: SNI 03-3424, (1994:25)

\section{Analisis Debit Banjir}

Hujan Kawasan (Daerah Tangkapan Air = DTA)

Ada 3 macam cara yang umum dipakai dalam menghitung hujan rata-rata kawasan, (Suripin, 2004:26) :

\section{1). Cara Rata-Rata Aljabar}

Merupakan metode yang paling sederhana dalam perhitungan hujan kawasan. Metode ini didasarkan pada asumsi bahwa semua pengukur hujan mempunyai pengaruh yang setara. Hujan kawasan diperoleh dari persamaan:

$\mathrm{P}=\frac{\mathrm{P}_{1}+\mathrm{P}_{2}+\mathrm{P}_{3}+\cdots \mathrm{Pn}_{\mathrm{n}}}{\mathrm{n}}=\frac{\sum_{\mathrm{i}=1}^{\mathrm{n}} \mathrm{P} 1}{\mathrm{n}}$

Keterangan :

$\mathrm{P}=$ curah hujan daerah rata-rata $(\mathrm{mm})$

$\mathrm{n}$ = banyaknya pegukur hujan

$\mathrm{P}_{1}, \mathrm{P}_{2}, \ldots \mathrm{Pn}=\mathrm{curah}$ hujan ditiap pos pengukur hujan (mm)

\section{2). Metode Poligon Thiessen}

Metode ini cocok untuk daerah datar dengan luas 500-5.000 km², dan jumlah pos pengukur hujan terbatas dibandingkan luasnya.
Hujan rata-rata DAS dapat dihitung dengan persamaan berikut:

$$
\begin{aligned}
& \mathrm{P}= \frac{\mathrm{P} 1 \mathrm{~A} 1+\mathrm{P} 2 \mathrm{~A} 2+\ldots+\mathrm{PnAn}}{\mathrm{A} 1+\mathrm{A} 2+\ldots+\mathrm{An}}= \\
& \frac{\sum_{\mathrm{i}=1}^{\mathrm{n}} \mathrm{PiAi}}{\sum_{\mathrm{i}=1}^{\mathrm{n}} \mathrm{Ai}} \ldots \ldots \ldots \ldots \ldots \ldots \ldots \ldots \ldots \ldots \ldots \ldots \ldots \ldots \ldots \ldots \ldots
\end{aligned}
$$

Keterangan :

$\mathrm{P}=$ curah hujan daerah rata-rata $(\mathrm{mm})$

$\mathrm{P}_{1}, \mathrm{P}_{2}, \ldots \mathrm{P}_{\mathrm{n}}=$ curah hujan di tiap titik pengamatan $1,2, \ldots \mathrm{n}(\mathrm{mm})$

$\mathrm{A}_{1}, \mathrm{~A}_{2}, \ldots \mathrm{A}_{\mathrm{n}}=$ luas areal poligon $1,2, \ldots \mathrm{n}$ $\left(\mathrm{km}^{2}\right)$

\section{3). Metode Isohyet}

Metode ishoyet cocok untuk daerah berbukit dan tidak teratur dengan luas lebih dari $5.000 \mathrm{~km}^{2}$. Hitung hujan rata-rata DAS dengan persamaan berikut:

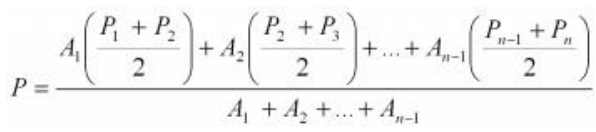

Atau

$$
P=\frac{\sum\left[A\left(\frac{P_{1}+P_{2}}{2}\right)\right]}{\sum A}
$$

Keterangan :

$\mathrm{P}_{1}, \mathrm{P}_{2}, \ldots \mathrm{P}_{\mathrm{n}}=$ curah hujan yang tercatat di pos pengukur hujan $1,2, \ldots, n$ (mm).

$\mathrm{n}=$ banyaknya pos pengukur hujan

$\mathrm{A}=$ luas bagian antara garis Isohyet 1 , $2, \ldots \mathrm{n}\left(\mathrm{km}^{2}\right)$

\subsubsection{Analisa Frekuensi}

Dalam analisis frekuensi data hujan atau data debit guna memperoleh nilai hujan rencana atau debit rencana, dikenal beberapa distribusi probabilitas yang sering digunakan, yaitu, (Kamiana, 2011:26) :

1). Distribusi gumbel

2). Distribusi log person tipe III

3). Distribusi log normal

4). Distribusi normal 


\section{| 115 | JUTEKS Jurnal Teknik Sipil}

Penentuan jenis distribusi probabilitas yang sesuai dengan data dilakukan dengan mencocokan parameter data tersebut dengan syarat masing-masing jenis distribusi seperti pada Tabel 2.10.

Tabel 2.10. Persyaratan Parameter Statistik Suatu Distribusi

\begin{tabular}{|c|c|l|}
\hline No & Distribusi & \multicolumn{1}{|c|}{ Persyaratan } \\
\hline 1 & Gumbel & $\begin{array}{l}\mathrm{C}_{\mathrm{s}}=1,14 \\
\mathrm{C}_{\mathrm{k}}=5,4\end{array}$ \\
\hline 2 & Normal & $\begin{array}{l}\mathrm{Cs}=0 \\
\mathrm{Ck}=3\end{array}$ \\
\hline 3 & Log & $\begin{array}{l}\mathrm{C}_{\mathrm{s}}=\mathrm{C}_{\mathrm{v}}{ }^{3}+3 \mathrm{C}_{\mathrm{v}} \\
\mathrm{C}_{\mathrm{k}}=\mathrm{C}_{\mathrm{v}}{ }^{8}+6 \mathrm{C}_{\mathrm{v}}{ }^{6}+15 \mathrm{C}_{\mathrm{v}}{ }^{4}+ \\
16 \mathrm{C}_{\mathrm{v}}{ }^{2}+3\end{array}$ \\
\hline 4 & Normal \\
\hline
\end{tabular}

Sumber : Kamiana, (2011:27)

Keterangan Tabel (2.10):

- Koefisien kepencengan $(\mathrm{Cs})=$

$$
\frac{n \sum_{i=1}^{i}(x i-x)^{3}}{(n-1)(n-2)(s)^{2}}
$$

- Koefisien kurtosis $(\mathrm{Ck})=$

$$
\frac{n^{2} \sum_{i=1}^{i}(x i-X) 4}{(n-1)(n-2)(n-3)(s) 4}
$$

- $\#$ = nilai rata-rata dari $\mathrm{X}=$.

$$
\frac{\sum_{i=1}^{n} X i}{n}
$$

- Standar deviasi $(\mathrm{Sd})=$

$$
\sqrt{\frac{\sum_{i=1}^{n}(\mathrm{Xi}-\mathrm{X})^{2}}{n-1}}
$$

- $\mathrm{Xi}=$ data hujan atau debit ke-i

- $\mathrm{n}=$ jumlah data

\section{Uji Distribusi Probabilitas}

Uji distrubusi probabilitas dimaksud untuk mengetahui apakah persamaan distribusi probabilitas yang dipilih dapat mewakili distribusi statistik sampel data yang dianalisis.

\section{Volume 2 Nomor 2 Oktober 2017}

Terdapat 2 metode pengujian distribusi probabilitas, yaitu: metode Chi_Kuadrat $\left(\mathrm{X}^{2}\right)$ dan metode Smirnov-Kolmogorof, (Kamiana, 2011:36).

\section{Hujan Rencana}

Hujan rencana $\left(\mathrm{X}_{\mathrm{T}}\right)$ adalah hujan dengan periode ulang tertentu (T) yang diperkirakan akan terjadi di suatu daerah pengaliran. (Kamiana, 2011:13).

Persamaan-persamaan untuk mencari peluang terjadinya hujan yaitu :

Peluang terjadinya $\mathrm{X} \geq \mathrm{X}_{\mathrm{T}}$ setiap tahun;

$\mathrm{P}\left(\mathrm{X} \geq \mathrm{X}_{\mathrm{T}}\right)=1 / \mathrm{T} \times 100 \%$

Peluang $\mathrm{X}<\mathrm{X}_{\mathrm{T}}$ setiap tahun;

$\mathrm{P}\left(\mathrm{X}<\mathrm{X}_{\mathrm{T}}\right)=(1-1 / \mathrm{T}) \times 100 \%$

Resiko atau peluang $\mathrm{X} \geq \mathrm{X}_{\mathrm{T}}$ paling tidak $1 \mathrm{kali}$ dalam rentang $\mathrm{n}$ tahun berurutan;

$\mathrm{P}\left(\mathrm{X} \geq \mathrm{X}_{\mathrm{T}}\right)^{\mathrm{n}}=1-(1-1 / \mathrm{T})^{\mathrm{n}} \times 100 \%$

Keterangan :

$\mathrm{P}=$ peluang $(\%)$

$\mathrm{T}=$ periode ulang (Tahun)

$\mathrm{X}=$ hujan $(\mathrm{mm})$

$\mathrm{X}_{\mathrm{T}}=$ hujan rencana dengan periode ulang $\mathrm{T}$ (mm)

\section{Perhitungan Debit Banjir}

Metode yang digunakan untuk menghitung debit banjir dengan besar limpasan yang terjadi yaitu dengan menggunakan salah satu metode dari metode Empiris yaitu metode Rasional. Persamaan matematik metode Rasional dinyatakan dalam bentuk, (Kamiana, 2011:82) :

$\mathrm{Q}=0,278 \times \mathrm{C} \times \mathrm{I} \times \mathrm{A}$

Keterangan :

$\mathrm{Q}=$ debit puncak limpasan permukaan $\left(\mathrm{m}^{3} / \mathrm{dtk}\right)$

$\mathrm{C}=$ angka pengaliran (tanpa dimensi)

$\mathrm{I}=$ intensitas curah hujan $(\mathrm{mm} / \mathrm{jam})$

$\mathrm{A}=$ luas daerah pengaliran $\left(\mathrm{Km}^{2}\right)$

Jika persamaan (2.50) dipergunakan untuk menghitung debit rencana dengan berbagai periode ulang maka notasinya dalam buku ditulis sebagai berikut:

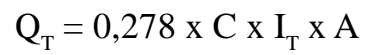


Keterangan :

$\mathrm{Q}_{\mathrm{T}} \quad=$ debit puncak limpasan permukaan dengan periode ulang $\mathrm{T}$ tahun atau debit rencana dengan periode ulang $\mathrm{T}$ tahun $\left(\mathrm{m}^{3} / \mathrm{dtk}\right)$

$\mathrm{C}=$ angka pengaliran (tanpa dimensi)

A = luas daerah pengaliran $\left(\mathrm{Km}^{2}\right)$

$\mathrm{I}_{\mathrm{T}} \quad=$ intensitas curah hujan dengan periode ulang $\mathrm{T}$ tahun $(\mathrm{mm} / \mathrm{jam})$.

\section{Perhitungan Debit Air Kotor}

Debit air kotor adalah debit yang berasal dari air buangan hasil aktifitas penduduk berupa air buangan rumah tangga. Dalam perhitungan jumlah air kotor diperkirakan berdasarkan kebutuhan air bersih di daerah studi dan perkiraan besarnya air buangan sebesar $90 \%$ dari kebutuhan standart air minum, (Suhardjono, 19984:32).

Kebutuhan air bersih secara umum diperkirakan berkisar antara 150-300 ltr/org/hr untuk keperluan rumah tangga, dan fasilitas umum berkisar antara 60-100 ltr/org/hr.

Untuk jumlah penduduk sebesar Pn, maka air kotor yang dibuang setiap $\mathrm{Km}^{2}$ dapat dihitung sebagai berikut :

$\mathrm{Qak}=($ Pn.q) $/ \mathrm{A}$.

Maka debit air kotor untuk masingmasing saluran drainase dapat dihitung dengan persamaan berikut :

Qki = Qakx Ai

Keterangan :

Qak = debit air kotor rata-rata $(\mathrm{lt} / \mathrm{dt} / \mathrm{Ha})$

$\mathrm{Pn} \quad$ jumlah penduduk

$\mathrm{q}=$ debit air buangan (lt/dt/orang)

$\mathrm{A} \quad=$ luas total wilayah $(\mathrm{Ha})$

Qki = debit air kotor per saluran (lt/dt)

$\mathrm{Ai}=$ luas tiap daerah pengaliran $(\mathrm{Ha})$

\section{Perhitungan Pertumbuhan Penduduk}

Pertumbuhan penduduk diperlukan untuk memprediksi jumlah air buangan, dengan menggunakan geometrik :

$\mathrm{Pn}=\mathrm{Po}(1+\mathrm{r})$
Keterangan :

Pn = jumlah penduduk pada tahun ke-n

Po $=$ jumlah penduduk pada tahun dasar

$r \quad=$ laju pertumbuhan penduduk

$\mathrm{n}=$ jumlah interval waktu.

\section{Perhitungan Debit Banjir Rencana}

Debit rencana merupakan debit yang dipakai untuk perhitungan bangunan air yang akan direncanakan. Debit rencana adalah penjumlahan dari debit air kotor dan air hujan. Berdasarkan data-data dan proses perhitungan maka diketahui debit air hujan (Qh) dan debit air kotor $(\mathrm{Qk})$ sehingga debit rencana:

$\mathrm{Qr}=\mathrm{Qh}+\mathrm{Qk}$

Keterangan :

$\mathrm{Qr}=$ debit banjir rencana

$\mathrm{Qk}=$ debit air kotor

$\mathrm{Qh}=$ debit air hujan

Untuk mengetahui kemampuan kapasitas saluran drainase terhadap debit rencana maka digunakan rumus :

$\mathrm{Q}=\mathrm{Qs}-\mathrm{Qp}$

Keterangan :

Qs = debit saluran $\left(\mathrm{m}^{3} / \mathrm{dtk}\right)$

$\mathrm{Qp}=$ debit rencana/debit air hujan dan debit air kotor $\left(\mathrm{m}^{3} / \mathrm{dtk}\right)$

\section{Menentukan Debit Aliran}

Faktor-faktor untuk menentukan debit aliran yaitu, (SNI 03-3424, 1994:12) :

\section{A. Intensitas Curah Hujan.}

Intensitas curah hujan (I) adalah rata-rata dari hujan yang lamanya sama dengan waktu konsentrasinya $\left(t_{c}\right)$ dengan masa ulang tertentu. Hubungan antara intensitas curah hujan dan lamanya hujan, digunakan rumus sebagai berikut, (Suripin, 2004:68) :

Mononobe

$I=\frac{R_{24}}{24}\left(\frac{24}{t c}\right)^{\frac{2}{3}}$

Keterangan :

I $\quad$ intensitas hujan $(\mathrm{mm} / \mathrm{jam})$ 
$\mathrm{R}_{24}=$ curah hujan maksimun harian (selama 24 jam) (mm)

tc $=$ Waktu konsentrasi (jam)

\section{Waktu Konsentrasi ( $\left.t_{c}\right)$}

1). Rumus Kirpich

$$
\mathrm{t}_{\mathrm{c}}=\frac{0,87 \times \mathrm{L}^{2}}{1000 \times \mathrm{S}}
$$

Keterangan :

$\mathrm{t}_{\mathrm{c}}=$ waktu konsentrasi (jam)

$\mathrm{L}=$ panjang lintasan air dari titik terjauh sampai titik yang ditinjau (Km)

$\mathrm{S}=$ kemiringan rata-rata daerah lintasan

2) Waktu konsentrasi aliran adalah waktu yang dibutuhkan air hujan yang jatuh diseluruh daerah tangkapan untuk mengalir ketitik yang ditinjau, (SNI, 1994:17).

Waktu konsentrasi dihitung dengan rumus:

$\mathrm{tc}=\mathrm{t}_{1}+\mathrm{t}$

$\mathrm{t}_{2}=\frac{\mathrm{L}}{60 . \mathrm{V}}$

Keterangan :

$\mathrm{t}_{1} \quad$ = Waktu untuk mencapai awal saluran (menit)

$\mathrm{t}_{2}=$ Waktu pengaliran (menit)

tc = waktu konsentrasi (jam)

nd $=$ Koefisien hambatan (Tabel 2.19)

Lo $=$ Jarak aliran dari titik terjauh sampai sarana drainase (Gambar 2.19)

$\mathrm{L}$ = Panjang saluran yang ditinjau (m)

$\mathrm{S}=$ Kemiringan daerah pengaliran

$\mathrm{V}=$ Kecepatan pengaliran $(\mathrm{m} / \mathrm{dtk})$

\section{METODE PENELITIAN}

Tahapan Penelitian

\section{a). Pengumpulan Data}

Data yang digunakan dalam penelitian ini adalah data primer dan sekunder. Data primer diperoleh melalui survey lapangan berupa data berupa ukuran data pengukuran dimensi saluran yang ada, kemiringan saluran, panjang masingmasing saluran. Termasuk pula, data-data kerusakan saluran. Sedangkan data sekunder diperoleh dari instansi terkait. data ini berupa peta topografi yang bersumber dari Dinas Pekerjaan Umum Provinsi Nusa Tenggara Timur (Sub Dinas Cipta Karya ) dan data curah hujan 10 tahun terakhir (2003-2012) yang bersumber dari Badan Meterologi dan Geofisika (BMG El Tari dan BMG Lasiana).

\section{b). Pengolahan Data}

Data primer yang diperoleh dari hasil survei, selanjutnya akan diolah. Hasil kompilasi data akan dijadikan dasar untuk menganalisa/menghitung debir rencana, menghitung debit saluran kondisi existing, dan selanjutnya mengevaluasi kondisi debit banjir rencana $\left(Q_{r}\right)$ terhadap Kapasitas saluran $\left(Q_{s}\right)$

\section{c). Alternatif Penanganan}

Dari hasil pengolahan dan analisa, selanjutnya ditentukan alternatif penanganan yang harus dilakukan terhadap genangan banjir di Jalan Cak Doko sesuai dengan hasil evaluasi kondisi debit terhadap kapasitas saluran.

\section{HASIL DAN PEMBAHASAN}

Kelurahan Oetete merupakan daerah dataran rendah, daerah ini mempunyai beberapa kawasan yang sering terjadi genangan air. Dalam penelitian ini yang menjadi daerah tinjauan yaitu daerah genangan air di Jalan Cak Doko (Depan SMA Negeri 1). Jaringan drainase diidentifikasi per ruas mulai dari Jalan Meranti sebelah kiri (ruas 1), Jalan Meranti sebelah kanan (ruas 2), dalam SMA 1 (ruas 3 \& ruas 4), Jalan Cak Doko sebelah kiri (ruas 5), Jalan Cak Doko sebelah kanan (ruas 6), dan diantara rumah warga (ruas 7), (skema jaringan terlampir). Kondisi eksisting jaringan drainase yang ada pada lokasi studi dapat dilihat pada Tabel 4.1. 
Tabel 4.1. Kondisi Jaringan Drainase Eksisting untuk Masing-Masing Ruas

\begin{tabular}{|c|c|c|c|c|c|c|c|c|}
\hline \multirow[b]{2}{*}{10} & \multirow{2}{*}{$\begin{array}{l}\text { Ruas } \\
\text { Saluran }\end{array}$} & \multirow{2}{*}{ Lolasi } & \multicolumn{2}{|c|}{ Elerai } & \multirow{2}{*}{$\begin{array}{c}\text { Beda Tingg } \\
\text { (II) }\end{array}$} & \multirow{2}{*}{$\begin{array}{c}\text { Paniang } \\
\text { Saluran (III) } \\
\end{array}$} & \multicolumn{2}{|c|}{ Dimensi Saluran } \\
\hline & & & Hulu & Hilir & & & $b(m)$ & $H(\mathbb{m})$ \\
\hline | & Ruas I & Jalan Nerati Setelat Kiri & 47.68 & 46.70 & 0.980 & 110 & 0.70 & 0.11 \\
\hline$?$ & Ruas? & Ialan Merariti Setetah Kanan & 45.80 & 4.70 & 1.100 & 110 & 0.60 & 0.60 \\
\hline 3 & Rux 3 & Dalam & 47.83 & 46.70 & 1.130 & j. & 0.60 & 0.60 \\
\hline t & Rusast & Dalam SMAI & 49,30 & 47.92 & 1,380 & 103 & 0.75 & 0.9 \\
\hline 5 & Rus 5 & Ialan Cak Doto Setetela Kiri & 47.61 & 45.62 & 1.990 & 183 & 0.80 & 0.70 \\
\hline 6 & Rus 6 & Jalan Cak Doto Setelan Kanan & 40.75 & 41,90 & 1.800 & 160 & 0.60 & 0.60 \\
\hline 7 & Ruas? & Diantara Rumal Warga RT25 & $4 . j 5$ & 43.87 & 0.680 & 74 & 0.70 & 0.7 \\
\hline
\end{tabular}

Sumber : Hasil Pengukuran

Berdasarkan hasil identifikasi di lapangan jaringan drainase yang ada di lokasi studi tersebut sudah tidak berfungsi dengan baik, sehingga sering terjadi genangan air pada musim hujan. Pada saluran tersebut terdapat banyak sekali sedimen dan sampah-sampah baik itu sampah organik maupun sampah non organik yang masuk ke dalam saluran sehingga menyebabkan penyempitan saluran. Genangan air yang terjadi sepanjang $\pm 15 \mathrm{~m}$, dan tinggi genangan $\pm 30 \mathrm{~cm}$. Kondisi genangan air di Jalan Cak Doko (Depan SMA 1), seperti pada gambar berikut:

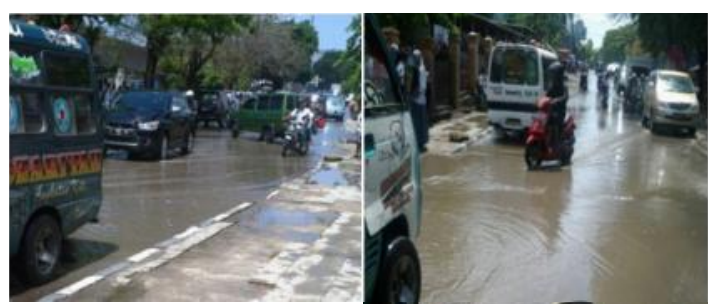

Gambar 4.1. Kondisi Genangan Air Di Jalan Cak Doko (Depan SMA1)
Tabel 4.2. Perhitungan Kemiringan Dasar Saluran (i) Eksisting Tiap Ruas

\begin{tabular}{|c|c|c|c|c|c|c|c|c|}
\hline Ruas & \multirow{2}{*}{ Liki } & \multicolumn{2}{|c|}{ Elexzi } & \multirow{2}{*}{$\begin{array}{c}\text { Bela Tingi } \\
\text { (II) }\end{array}$} & \multirow{2}{*}{$\begin{array}{l}\text { Panjang } \\
\text { Saluran (m) }\end{array}$} & \multicolumn{2}{|c|}{ Dimensi Saluran } & \multirow{2}{*}{ 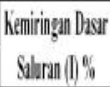 } \\
\hline Lran & & Holu & Hilir & & & $h(m)$ & $H(m)$ & \\
\hline UISI I & 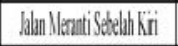 & 47.68 & 4.9 .7 & 0980 & 110 & 0.70 & 0.70 & 0.89 \\
\hline uns? & 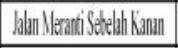 & 45.80 & H.7. & 1.100 & 110 & 0.60 & 0.60 & 1.00 \\
\hline Alsis? & DuammSHAI & 47.83 & 4.070 & 1.130 & i2 & 0.60 & 0.60 & 217 \\
\hline SuISt & Dukm SUIAI & 49.3 & 79. & 1,380 & 103 & 077 & 090 & 134 \\
\hline us: & Jalan Cak Dovo Setedh Kiri & 47.61 & 1562 & 1990 & 183 & 0.80 & 0.70 & 1.99 \\
\hline 1156 & 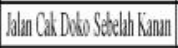 & 46.75 & $H 00$ & 1.850 & 160 & 0.60 & 0.60 & 1.16 \\
\hline य15? & 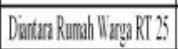 & 4.5 & 4.88 & 0.680 & 74 & 0.7 .0 & 0.70 & 092 \\
\hline
\end{tabular}

Sumber : Hasil Perhitungan

Tabel 4.3. Perhitungan Kapasitas Saluran Eksisting (Qs) Tiap Ruas

\begin{tabular}{|c|c|c|c|c|c|c|c|c|c|c|}
\hline & \multirow{3}{*}{ Ihi } & \multirow{3}{*}{ 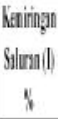 } & \multirow{2}{*}{\multicolumn{2}{|c|}{ linesidyl }} & \multirow{3}{*}{$\begin{array}{l}\text { Wuffistan } \\
\text { uninizgn }\end{array}$} & \multirow{3}{*}{$\mid \begin{array}{l}\text { Keling } \\
\text { Bisil } \\
\text { Plin }\end{array}$} & \multirow{3}{*}{ 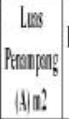 } & \multirow{3}{*}{ 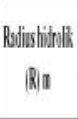 } & \multirow{3}{*}{ 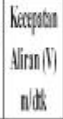 } & \multirow{3}{*}{$\begin{array}{l}\text { Qbisisin } \\
\text { Clisisno } \\
\text { (QSinisith }\end{array}$} \\
\hline & & & & & & & & & & \\
\hline & & & b(i) & $H(i i)$ & & & & & & \\
\hline & 8 & 104 & (ii) & $1,1]$ & 613 & 2110 & (H) & & (bi) & 0,1507 \\
\hline & Wialliand & 1.4 & (166) & $|, 9|$ & 145 & 18) & bit & & 1007 & 1.964) \\
\hline & Dim NAt & !.17 & $(66)$ & $\mid(b)$ & Q13 & (8) & 1.36 & & 5) 17 & 1,1360 \\
\hline & Thingle. & list & 073 & |9] & 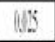 & 5 & if & & (14) & (1) 1728 \\
\hline & Wrick Dotes & 1,9 & (88) & (1,) & 10.5 & 12) & $|N|$ & & 14:4) & 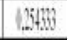 \\
\hline & tolst & 1,16 & 660 & (ig) & 010.5 & (B) & 1,36 & 60 & $02 x_{3}$ & t.lll: \\
\hline & 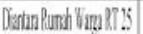 & 19. & 0.0 & (1.1) & 105 & 2110) & ith & & (3.4. & 15in \\
\hline
\end{tabular}

Sumber : Hasil Perhitungan

Tabel 4.4. Perhitungan Debit Hujan (Qh) Beberapa Kala Ulang untuk Tiap Ruas

\begin{tabular}{|c|c|c|c|c|c|} 
Ruas & $\mathbf{T r}$ & $\mathbf{I}$ & $\mathbf{C}$ & $\mathbf{A}$ & $\mathbf{Q h}$ \\
\cline { 2 - 6 } Saluran & $(\mathbf{T a h u n})$ & $\mathbf{( m m} / \mathbf{j a m})$ & & $\mathbf{( H a )}$ & $\left(\mathbf{m}^{\mathbf{3}} / \mathbf{d t k}\right)$ \\
\hline \multirow{4}{*}{ Ruas 1 } & 5 & 231,570 & 0,484 & 1,8227 & 0,567921 \\
\cline { 2 - 6 } & 10 & 269,733 & 0,484 & 1,8227 & 0,661515 \\
\cline { 2 - 6 } & 25 & 325,787 & 0,484 & 1,8227 & 0,798986 \\
\cline { 2 - 6 } & 50 & 370,625 & 0,484 & 1,8227 & 0,908950 \\
\cline { 2 - 6 } & 100 & 418,731 & 0,484 & 1,8227 & 1,026929 \\
\hline \multirow{5}{*}{ Ruas 2 } & 5 & 210,010 & 0,509 & 4,6788 & 1,390391 \\
\cline { 2 - 6 } & 10 & 248,451 & 0,509 & 4,6788 & 1,644894 \\
\cline { 2 - 6 } & 25 & 300,083 & 0,509 & 4,6788 & 1,986728 \\
\cline { 2 - 6 } & 50 & 341,383 & 0,509 & 4,6788 & 2,260159 \\
\cline { 2 - 6 } & 100 & 385,693 & 0,509 & 4,6788 & 2,553517 \\
\hline \multirow{5}{*}{ Ruas 3 } & 5 & 405,773 & 0,435 & 2,4430 & 1,198783 \\
\cline { 2 - 6 } & 10 & 480,046 & 0,435 & 2,4430 & 1,418209 \\
\cline { 2 - 6 } & 25 & 579,807 & 0,435 & 2,4430 & 1,712935 \\
\cline { 2 - 6 } & 50 & 659,605 & 0,435 & 2,4430 & 1,948684 \\
\cline { 2 - 6 } & 100 & 745,219 & 0,435 & 2,4430 & 2,201615 \\
\hline \multirow{5}{*}{ Ruas 4 } & 5 & 318,963 & 0,402 & 2,4430 & 0,870832 \\
\cline { 2 - 6 } & 10 & 377,346 & 0,402 & 2,4430 & 1,030230 \\
\cline { 2 - 6 } & 25 & 455,764 & 0,402 & 2,4430 & 1,244326 \\
\cline { 2 - 6 } & 50 & 518,491 & 0,402 & 2,4430 & 1,415584 \\
\cline { 2 - 6 } & 100 & 585,789 & 0,402 & 2,4430 & 1,599321 \\
\hline
\end{tabular}




\begin{tabular}{|c|c|c|c|c|c|}
\hline & 5 & 212,816 & 0,577 & 2,3794 & 0,8123 \\
\cline { 2 - 6 } & 10 & 251,770 & 0,577 & 2,3794 & 0,9609 \\
\cline { 2 - 6 } & 25 & 304,091 & 0,577 & 2,3794 & 1,1606 \\
\cline { 2 - 6 } & 50 & 345,943 & 0,577 & 2,3794 & 1,3204 \\
\cline { 2 - 6 } & 100 & 390,845 & 0,577 & 2,3794 & 1,4917 \\
\hline \multirow{4}{*}{ Ruas 6 } & 5 & 186,286 & 0,627 & 0,8913 & 0,289412 \\
\cline { 2 - 6 } & 10 & 220,385 & 0,627 & 0,8913 & 0,342388 \\
\cline { 2 - 6 } & 25 & 266,184 & 0,627 & 0,8913 & 0,413541 \\
\cline { 2 - 6 } & 50 & 302,819 & 0,627 & 0,8913 & 0,470456 \\
\cline { 2 - 6 } & 100 & 342,123 & 0,627 & 0,8913 & 0,531519 \\
\hline \multirow{4}{*}{ Ruas 7 } & 5 & 279,763 & 0,601 & 0,2516 & 0,117603 \\
\cline { 2 - 6 } & 10 & 330,971 & 0,601 & 0,2516 & 0,139130 \\
\cline { 2 - 6 } & 25 & 399,752 & 0,601 & 0,2516 & 0,168043 \\
\cline { 2 - 6 } & 50 & 454,770 & 0,601 & 0,2516 & 0,191171 \\
\cline { 2 - 6 } & 100 & 513,797 & 0,601 & 0,2516 & 0,215984 \\
\hline
\end{tabular}

Sumber : Hasil Perhitungan

Tabel 4.5. Perhitungan Debit Air Kotor untuk Tiap Ruas Saluran

\begin{tabular}{|c|c|c|c|c|c|c|}
\hline $\mathrm{N}_{0}$ & \begin{tabular}{|c|} 
Ruas \\
Saluran \\
\end{tabular} & Lohasi & $\begin{array}{l}\text { Panjang } \\
\text { Ruas (m) } \\
\end{array}$ & $\begin{array}{l}\text { Jumlah } \\
\text { Rumah }\end{array}$ & \begin{tabular}{|c|} 
Jumlah Penduduk \\
(orang)
\end{tabular} & $\begin{array}{l}\text { Debit Air Kotor } \\
\text { (0ak) m3/dth }\end{array}$ \\
\hline 1 & Ruas I & Jalan Meranti Setelah Kin & 110 & 18 & 90 & 0,000084 \\
\hline 2 & Ruas2 & Jalan Meranti Sebelah Kanan & 110 & 18 & 90 & 0.000084 \\
\hline 3 & Russ 3 & Dalam SMA 1 & 52 & 8 & 40 & 0.000037 \\
\hline 4 & Ruas 4 & DalamSMA 1 & 103 & 16 & 80 & 0.000074 \\
\hline 5 & Ruas 5 & Jalan Cak Doko Setelah Kiri & 183 & 29 & 145 & 0.000135 \\
\hline 6 & Ruas 6 & Jalan Cak Doko Setelah Kanan & 160 & 26 & 130 & 0.000121 \\
\hline 7 & Ruas? & Diantara Rumah Warga RT 25 & 74 & 12 & 60 & 0.000056 \\
\hline \multicolumn{3}{|r|}{ Jumlah } & 792 & 127 & 635 & 0.000591 \\
\hline
\end{tabular}

Sumber : Hasil Perhitungan

Tabel 4.6. Perhitungan Debit Banjir Rencana (Qr) untuk Tiap Ruas

\begin{tabular}{|c|c|c|c|c|c|c|}
\hline & Ruas & \multirow{2}{*}{ Lolasi } & \multicolumn{2}{|c|}{ 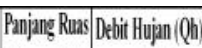 } & \multirow{2}{*}{$\begin{array}{l}\text { Detit fir hotor } \\
\text { (0ali midth }\end{array}$} & \multirow{2}{*}{$\begin{array}{l}\text { Delit Rencana } \\
\text { (Orimisidth }\end{array}$} \\
\hline${ }^{10}$ & Saluran & & Saluran (m) & midith & & \\
\hline 1 & Rusas I & Jaban Meranti Setebla Kiñ & 110 & 0569921 & $0.00004-1$ & 0.56005 \\
\hline 2 & Ruses? & Whan Nerantif Stedah Kanan & 110 & 1,39039 & 0.00004 & $1394+75$ \\
\hline 3 & Rusas 3 & Datan SYAI I & $\$ 2$ & 1.198783 & 0.000037 & 19882) \\
\hline+ & Rusas 4 & Datam SMAI I & 103 & 1088317? & 0.900074 & 0.883591 \\
\hline 5 & Rus 5 & talan Cak Doko Schelath Kiri & 183 & 0.827548 & 0.900135 & 0.87768 \\
\hline 0 & Ruess 6 & 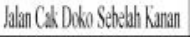 & 160 & 0.289412 & 0.000121 & 0.289533 \\
\hline$?$ & Rusis & Diantara Rumand Narga RT 25 & 77 & 0.119100 & 0,000036 & 0.11915 \\
\hline
\end{tabular}

Sumber : Hasil Perhitungan
Tabel 4.7. Perhitungan Evaluasi Kondisi Debit Banjir Rencana (Qr) Terhadap Kapasitas Saluran Eksisting (Qs) untuk Tiap Ruas

\begin{tabular}{|c|c|c|c|c|c|c|}
\hline & $\begin{array}{l}\text { Ruses } \\
\text { Saluran }\end{array}$ & Lohasi & $\begin{array}{c}\text { Panjang Ruas } \\
\text { Saluran (m) }\end{array}$ & $\begin{array}{l}\text { QSalurall } \\
\text { Eksisting (QS) }\end{array}$ & $\begin{array}{l}\text { Detit Rencana } \\
(\text { Orimidth }\end{array}$ & tern \\
\hline & Ruas| & dabn Neranti S Sth & 110 & 0,153798 & 0,560004 & as \\
\hline & Ruas? & Aalan Meral & 110 & 0,090000 & 1390475 & (14limpo \\
\hline & Ruas? & Dalam SWIAI & i2 & 0,218320 & 1,198820 & impas \\
\hline & Rusat & Dalam S. & 103 & 0,477028 & 0.883991 & impas \\
\hline & Ruas: & 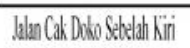 & 183 & $0.25+333$ & 0,827683 & impas \\
\hline f & Ruas6 & Jala Cak Doko Sectelah Kanan & 160 & $0,0,11360$ & 0.285533 & Melimpas \\
\hline & Ruas? & Diantara Rumah Wraga RTLS & 74 & 0,159892 & 0.119156 & Tiddk Melinos \\
\hline
\end{tabular}

Sumber : Hasil Analisa

Penampang saluran rencana:

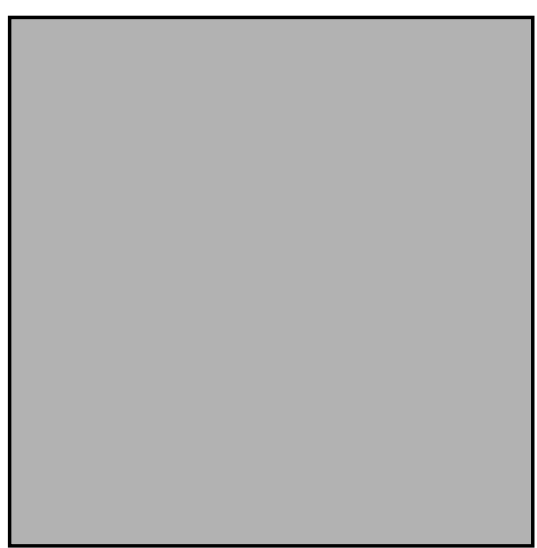

Gambar 4.2. Penampang Saluran Rencana di Ruas 1 (Jalan Meranti sebelah kiri)

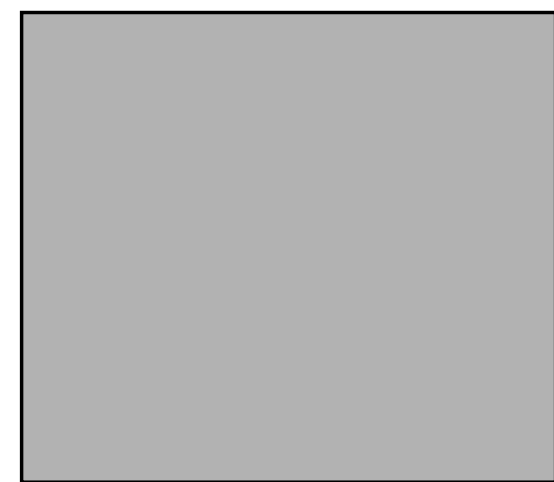

Gambar 4.3. Penampang Saluran Rencana di Ruas 2 (Jalan Meranti sebelah kanan) 


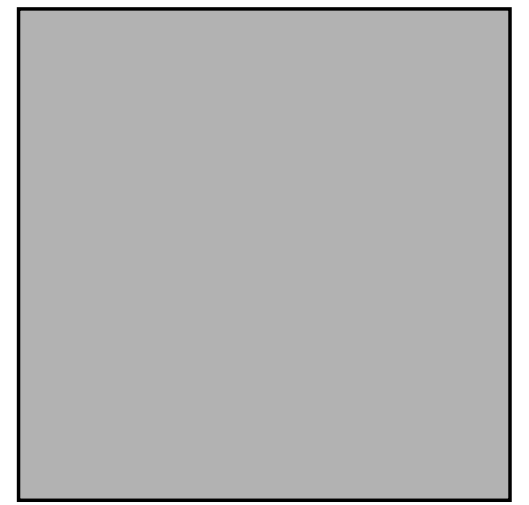

Gambar 4.4. Penampang Saluran Rencana di Dalam SMAN 1 Kupang

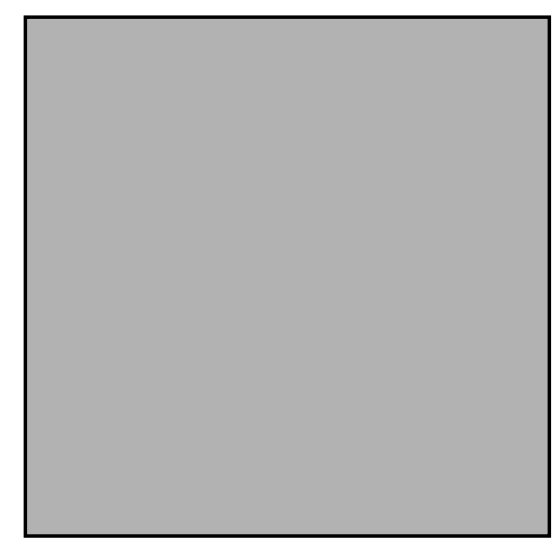

Gambar 4.5. Penampang Saluran Rencana di Jalan Cak Doko

\section{KESIMPULAN DAN SARAN}

\subsection{Kesimpulan :}

1.Berdasarkan hasil identifikasi di lapangan terhadap jaringan drainase yang ada di lokasi studi, terlihat bahwa saluran drainase secara umum sudah tidak berfungsi dengan baik, karena di dalam saluran terdapat banyak sekali sedimen dan sampah-sampah, baik itu sampah organik maupun sampah non organik sehingga menyebabkan penyempitan saluran.

2.Genangan banjir di jalan Cak Doko (depan SMAN I) terjadi karena beberapa hal, antara lain adanya perubahan penggunaan lahan, di mana banyak daerah resapan yang kini telah beralih fungsi menjadi kawasan perumahan, sekolah, dan gedung lainnya, selain itu lahan- lahan kosong di sekitar gedung dan permukiman, banyak yang sudah dibeton, atau dipaving, sehingga mengurangi lahan untuk peresapan, serta adanya penyempitan saluran akibat sedimen dan sampah, sehingga saluran drainase tidak lagi mampu menampung air hujan, yang akhirnya menyebabkan luapan yang menggenangi daerah-daerah cekungan, terutama di sekitar jalan Cak Doko.

3.Berdasarkan hasil evaluasi debit banjir rencana periode kala ulang 5 tahun terhadap kapasitas saluran eksisting diperoleh kapasitas saluran (Qs) lebih kecil dari debit banjir rencana (Qr) sehingga kapasitas saluran eksisting tidak dapat menampung debit banjir yang terjadi. Saluran drainase eksisting juga tidak berfungsi dengan baik yang disebabkan terdapat banyak sekali sedimen dan sampah baik itu sampah organik maupun sampah non organik yang masuk ke dalam saluran sehingga menyebabkan penyempitan saluran.

4.Dari hasil evaluasi kondisi debit banjir rencana terhadap kapasitas saluran eksisting, maka diperoleh pada ruas 1 sampai ruas 6 kapasitas saluran (Qs) lebih kecil dari debit banjir rencana $(\mathrm{Qr})$, sehingga saluran drainase pada ruas 1 sampai ruas 6 tersebut tidak dapat menampung debit banjir rencana. Oleh kerena itu, perlu direkomendasikan untuk merencanakan dimensi saluran berdasarkan hasil perhitungan debit banjir rencana (Qr) kala ulang 5 tahun agar dapat menampung dan mengalirkan debit air hujan dan debit air kotor yang terjadi.

\subsection{Saran :}

Dari kesimpulan di atas maka dapat disarankan agar :

1.Perlu adanya kesadaran yang tinggi dari masyarakat yang ada di sekitar wilayah studi agar dapat menjaga kebersihan, dengan tidak membuang sampah sembarangan, selalu menjaga kebersihan saluran drainase yang ada dengan secara rutin membersihkan saluran dari sedimen dan sampah yang tertimbun di saluran, sehingga saluran drainase tersebut dapat berfungsi dengan baik. 
$\square$ 121 JUTEKS Jurnal Teknik Sipil

2.Perlu adanya lubang-lubang peresapan di setiap rumah/gedung untuk mengurangi limpasan air hujan yang dapat menyebabkan genangan banjir.

\section{DAFTAR PUSTAKA}

Dep. PU. 1986. Standar Perencanaan Irigasi, Kriteria Perencanaan Bangunan Utama., Galang Persada, Bandung.

Hasmar Halim, H., A., 2011, Drainase Terapan, UII Press, Yogyakarta.

\section{Volume 2 Nomor 2 Oktober 2017}

Kamiana, I Made, 2011, Teknik Perhitungan Debit Rencana Bangunan Air, Graha Ilmu, Yogyakarta.

Mulyanto H., R., 2013, Penataan Drainase Perkotaan, Graha Ilmu, Yogyakarta.

Suhardjono, 1984, Drainase, Universitas Brawijaya, Malang.

Suripin, 2004, Drainase Perkotaan yang Berkelanjutan, Andi, Yogyakarta.

SNI 03-3424, 1994, Tata Cara Perencanaan Drainase Permukaan Jalan, Jakarta. 